\title{
Transition of social welfare in the European country clubs
}

\author{
George A. Christodoulakis ${ }^{a}, 1$, Emmanuel C. Mamatzakis ${ }^{\mathrm{b}, *}$ \\ ${ }^{\text {a } M a n c h e s t e r ~ B u s i n e s s ~ S c h o o l, ~ U n i v e r s i t y ~ o f ~ M a n c h e s t e r, ~ M B S ~ C r a w f o r d ~ H o u s e, ~ B o o t h ~ S t r e e t ~ W e s t, ~ M a n c h e s t e r ~ M 15 ~ 6 P B, ~ U K ~}$ \\ b Department of Economics, University of Piraeus, 80 M. Karaoli and Dimitriou street, Piraeus 185 34, Greece
}

\section{A R T I C L E I N F O}

\section{Article history:}

Received 15 October 2009

Received in revised form 22 April 2010

Accepted 5 May 2010

Available online 12 May 2010

\section{Keywords:}

Social clubs

Monte Carlo Integration

Transition matrix

JEL classification:

C1

I3

\section{Introduction}

Social welfare presents symptoms of chronic heterogeneity in EU (European Commission, 2006). This heterogeneity has led some countries within the EU to call for protectionist measures, including barriers to labor. This paper is the first attempt to investigate integration in social welfare in EU using club analysis that fits the stylised heterogeneity within the EU in terms of social policies (see Bertola, 2007). The notion of the formation of different social systems, mirroring at different social clubs, first appears in the EspingAndersen (1990), followed by Bertola (2007). We identify four social welfare clubs: the Nordic club (Denmark, Finland and Sweden, and Netherlands), the Continental club (Austria, Belgium, France and Germany), Anglo-Saxon club (UK and Ireland) and last the Southern club (Greece, Italy, Portugal and Spain). We use a Markov process to estimate the transition probabilities matrix of social welfare in EU by adopting a Bayesian approach and Monte Carlo Integration ( $\mathrm{MCI})$.

\section{Bayesian estimation of first order Markov transition probabilities}

We shall assume that the analyst observes the sample aggregate proportions of objects in each country club for every time period $t$. The

\footnotetext{
* Corresponding author. Tel.: +30 2104142297.

E-mail addresses: george.christodoulakis@mbs.ac.uk (G.A. Christodoulakis), tzakis@unipi.gr (E.C. Mamatzakis).

1 Tel.: +441613066402.
}

probability of the joint event that an object $z_{t}$ falls in two different states, $s_{i}$ and $s_{j}$, in two sequential periods, and it is written as

$\operatorname{Pr}\left(z_{t}=s_{j}, z_{t-1}=s_{i}\right)=\operatorname{Pr}\left(z_{t-1}=s_{i}\right) \operatorname{Pr}\left(z_{t}=s_{j} \mid z_{t-1}=s_{i}\right)$

which recursively yields

$\operatorname{Pr}\left(z_{t}=s_{j}\right)=\sum_{i} \operatorname{Pr}\left(z_{t-1}=s_{i}\right) \operatorname{Pr}\left(z_{t}=s_{j} \mid z_{t-1}=s_{i}\right)$

The state, $s_{i}$ takes the form of four mutually exclusive country clubs, which are the Nordic (C1), the Continental (C2), the Southern (C3) and the Anglo-Saxon (C4). We are interested in estimating the conditional transition probabilities between social clubs, forming the time homogeneous transition probability matrix $P$.

$P=\left[\begin{array}{llll}p_{\mathrm{C} 1, C 1} & p_{\mathrm{C} 1, \mathrm{C} 2} & p_{\mathrm{C} 1, \mathrm{C} 3} & p_{\mathrm{C} 1, \mathrm{C} 4} \\ p_{\mathrm{C} 2, \mathrm{C} 1} & p_{\mathrm{C} 2, \mathrm{C} 2} & p_{\mathrm{C}, \mathrm{C} 3} & p_{\mathrm{C}, \mathrm{C} 4} \\ p_{\mathrm{C} 3, \mathrm{C} 1} & p_{\mathrm{C} 3, \mathrm{C} 2} & p_{\mathrm{C} 3, \mathrm{C} 3} & p_{\mathrm{C} 3, \mathrm{C}} \\ p_{\mathrm{C} 4, \mathrm{C} 1} & p_{\mathrm{C} 4, \mathrm{C} 2} & p_{\mathrm{C} 4, \mathrm{C} 3} & p_{\mathrm{C} 4, \mathrm{C} 4}\end{array}\right]$

The conditional transition probabilities in Eq. (2) represent the entries of a row in matrix $P$. The stochastic matrix $P$ will be representative of a stochastic process only if it is associated to a converging generator matrix $G$, which is ensured if and only if $P$ is diagonal dominant. Therefore, the transition probability matrix $P$ is subject to constraints: its entries should be non-negative, each row sums to unit and every diagonal element exceeds 0.5 . 
We then transform the recursive relation Eq. (2) into an empirical model by replacing the unconditional probabilities with observed aggregate proportions $\boldsymbol{q}_{j}$ and adding a random error term $\boldsymbol{u}_{j}$. Then, the conditional transition probabilities can be treated as unknown parameters $\beta_{i j}$ and Eq. (2) can be written as:

$q_{j, t}=\sum_{i} q_{i, t-1} \beta_{i j}+u_{j, t}$

where $q_{j, t}$ is the proportion of value or objects in the class $j$ at time $t$ over total value or objects. When a finite time series sample of $T$ observations is available and conditional transition probabilities are properly constrained, Eq. (3) can be written as:

$\boldsymbol{q}_{j}=X_{j} \beta_{j}+u_{j}$

s.t.

$1^{\prime} \beta_{j}=1, \quad \beta_{j} \geq 0, \quad \beta_{j i}>0.5$ for $j=i$

where $\boldsymbol{q}$ is a vector of $T$ observations of portfolio returns, $X$ a matrix of $T$ observations for $K$ credit quality classes, $\beta$ a vector of $K$ conditional transition probabilities, 1 is a vector of units and $\boldsymbol{u} \sim N\left(0, \sigma^{2} I\right)$.

By restating model Eq. (4) in deviation form from the $k$-th country club proportion, we effectively impose the equality constraint, so that

$\boldsymbol{q}_{j}^{*}=X_{j}^{*} \boldsymbol{\beta}_{j}^{*}+\boldsymbol{u}_{j}$

s.t.

$\beta_{j}^{*} \geq 0, \quad \beta_{j i}^{*}>0.5$ for $j=i$

where the new variables are now expressed in deviation form and the $t$-th elements are given by $q_{t}^{*}=q_{t}-x_{k, t}$ and $x_{i, t}^{*}=x_{i, t-1}-x_{k, t-1}$, where $i=1, \ldots, K-1$ is the $i$-th column of $X$. The vector $\beta^{*}$ has $K-1$ elements whilst the $K$-th beta can now be obtained from the constraint $1-1^{\prime} \beta^{*}$. All elements of $X^{*}$ are assumed to be independent of each other and of $u, \beta^{*}$ and $\sigma^{2}$. Then Bayes law states that the posterior density of $\beta^{*}$ and $\sigma^{2}$ is:

$\operatorname{Posterior}\left(\beta^{*}, \sigma^{2} \mid \boldsymbol{q}^{*}, X^{*}\right)=\operatorname{Likelihood}\left(\beta^{*}, \sigma^{2} \mid \boldsymbol{q}^{*}, X^{*}\right) \times \operatorname{Prior}\left(\beta^{*}, \sigma^{2}\right)$

where we have dropped the country club subscript $j$. We follow van Dijk and Kloek (1980) and use a prior that is composed of an uninformative component for $\sigma^{2}$ and an informative one for $\beta^{*}$ which captures our existing knowledge for the parameter inequality restrictions. ${ }^{2}$ By independence:

$\operatorname{Prior}\left(\beta^{*}, \sigma^{2}\right)=\sigma^{-1} \mathrm{~T}\left(\beta^{*}\right)$

where

$\mathrm{T}\left(\beta^{*}\right)= \begin{cases}1 & \text { if } 1^{\prime} \beta^{*} \leq 1 \text { and } \beta^{*} \geq 0 \\ 0 & \text { otherwise }\end{cases}$

Assuming multivariate normality for $u$ and integrating out $\sigma$, the marginal posterior probability density function of vector $\beta^{*}$ is a multivariate $t$ with mean zero, variance $\frac{\lambda}{(\lambda-2) \hat{\sigma}^{2}} X^{\prime *} X^{*}$ and $\lambda=v$ degrees of freedom.

Following Kloek and van Dijk (1978), for any function $R($.$) , the$ point estimator of $R\left(\boldsymbol{\beta}^{*}\right)$ is given by:

$E\left(R\left(\beta^{*}\right) \mid \boldsymbol{y}^{*} X^{*}\right)=\frac{\int R\left(\beta^{*}\right) \text { Posterior }\left(\beta^{*} \mid \boldsymbol{q}^{*} X^{*}\right) d \beta^{*}}{\int \text { Posterior }\left(\beta^{*} \mid \boldsymbol{q}^{*} X^{*}\right) d \beta^{*}}$.

\footnotetext{
${ }^{2}$ For details on the uninformative and informative components see Christodoulakis (2007)
}

Table 1

The one-step transition probability matrix for social expenditure (\% of GDP).

\begin{tabular}{lllll}
\hline & \multicolumn{4}{l}{ Total expenditure (\% of GDP) } \\
\cline { 2 - 5 } & $\mathrm{C}_{1}$ & $\mathrm{C}_{2}$ & $\mathrm{C}_{3}$ & $\mathrm{C}_{4}$ \\
\hline $\mathrm{C}_{1}$ & 0.662 & 0.136 & 0.059 & 0.143 \\
$\mathrm{C}_{2}$ & 0.164 & 0.653 & 0.087 & 0.096 \\
$\mathrm{C}_{3}$ & 0.098 & 0.128 & 0.576 & 0.198 \\
$\mathrm{C}_{4}$ & 0.086 & 0.092 & 0.243 & 0.579 \\
& & & & \\
& Social protection benefits (\% of GDP) & & $\mathrm{C}_{4}$ \\
\cline { 2 - 5 } & $\mathrm{C}_{1}$ & $\mathrm{C}_{2}$ & $\mathrm{C}_{3}$ & 0.107 \\
& 0.697 & 0.138 & 0.057 & 0.101 \\
$\mathrm{C}_{1}$ & 0.147 & 0.634 & 0.118 & 0.206 \\
$\mathrm{C}_{2}$ & 0.097 & 0.121 & 0.575 & 0.589 \\
$\mathrm{C}_{3}$ & 0.092 & 0.149 & 0.170 & \\
$\mathrm{C}_{4}$ & & &
\end{tabular}

Estimator Eq. (10) can be implemented numerically by using an approximation for the posterior distribution, an importance function $\operatorname{Im} p\left(\boldsymbol{\beta}^{*}\right)$, from which random draws of $\boldsymbol{\beta}^{*}$ will be drawn. It can be shown that for $\boldsymbol{\beta}_{1}^{*}, \boldsymbol{\beta}_{2}^{*}, \ldots, \boldsymbol{\beta}_{N}^{*}$ being a set of $N$ random draws from $\operatorname{Im} p\left(\boldsymbol{\beta}^{*}\right)$, then:

$\lim _{N \rightarrow \infty} \frac{1}{N} \sum_{i=1}^{N} \frac{R\left(\beta_{i}^{*}\right) \text { Posterior }\left(\beta_{i}^{*} \mid q^{*} X^{*}\right)}{\operatorname{Im} p\left(\beta_{i}^{*}\right)}=E\left(R\left(\beta^{*}\right) \mid \boldsymbol{q}^{*} X^{*}\right)$

apart from a normalizing constant which can be calculated separately. In this case our estimator is reduced to $\frac{1}{N} \sum_{i=1}^{N} R\left(\beta_{i}^{*}\right) \mathrm{T}\left(\beta_{i}^{*}\right)$. Thus, our simulation procedure generates $\beta_{i}^{*}=\boldsymbol{b}+A z_{i}\left(\frac{\lambda}{w_{i}^{\prime} w_{i}}\right)^{\frac{1}{2}}$, where $\boldsymbol{b}$ is the least squares estimate, $A$ comes from the Cholesky decomposition of the least-squares covariance matrix, $z$ is a $K-1$ vector of standard normal variables and $w$ is a $\lambda$ vector of standard normal variables. Thus our parameter estimates can now be obtained using Eq. (9) and $R\left(\beta_{i}^{*}\right)=\beta_{i}^{*}$.

\section{The distribution dynamics}

Our data comes from Eurostat (2006) and include poverty risk, social transfers, employment and unemployment from 1995 to 2006. Probabilities on the main diagonals show the likelihood of the proportion of the variable under investigation remaining in the same club next period. The upper off-diagonal probabilities show the likelihood of transition to less generous social security systems that could be seen, if the aim is to raise social welfare and thus social expenditure, as a downgrade. Similarly, the lower off-diagonal

Table 2

The one-step transition probability matrix for risk of poverty.

\begin{tabular}{|c|c|c|c|c|}
\hline & \multicolumn{4}{|c|}{ Risk of poverty rate before social transfers } \\
\hline & $\mathrm{C}_{1}$ & $\mathrm{C}_{2}$ & $\mathrm{C}_{3}$ & $\mathrm{C}_{4}$ \\
\hline $\mathrm{C}_{1}$ & 0.663 & 0.117 & 0.134 & 0.086 \\
\hline $\mathrm{C}_{2}$ & 0.074 & 0.607 & 0.155 & 0.165 \\
\hline$C_{3}$ & 0.100 & 0.155 & 0.591 & 0.155 \\
\hline \multirow[t]{3}{*}{$\mathrm{C}_{4}$} & 0.130 & 0.190 & 0.095 & 0.585 \\
\hline & \multicolumn{4}{|c|}{ Risk of poverty rate after social transfers } \\
\hline & $\mathrm{C}_{1}$ & $\mathrm{C}_{2}$ & $\mathrm{C}_{3}$ & $\mathrm{C}_{4}$ \\
\hline $\mathrm{C}_{1}$ & 0.593 & 0.089 & 0.124 & 0.195 \\
\hline $\mathrm{C}_{2}$ & 0.098 & 0.584 & 0.124 & 0.194 \\
\hline $\mathrm{C}_{3}$ & 0.097 & 0.187 & 0.600 & 0.116 \\
\hline $\mathrm{C}_{4}$ & 0.106 & 0.092 & 0.209 & 0.594 \\
\hline
\end{tabular}


Table 3

The one-step transition probability matrix for labor.

\begin{tabular}{|c|c|c|c|c|}
\hline & \multicolumn{4}{|c|}{ Employment } \\
\hline & $\mathrm{C}_{1}$ & $\mathrm{C}_{2}$ & $\mathrm{C}_{3}$ & $\mathrm{C}_{4}$ \\
\hline $\mathrm{C}_{1}$ & 0.610 & 0.271 & 0.072 & 0.047 \\
\hline $\mathrm{C}_{2}$ & 0.145 & 0.599 & 0.129 & 0.126 \\
\hline $\mathrm{C}_{3}$ & 0.169 & 0.086 & 0.657 & 0.088 \\
\hline \multirow[t]{3}{*}{$\mathrm{C}_{4}$} & 0.142 & 0.076 & 0.117 & 0.665 \\
\hline & \multicolumn{4}{|c|}{ Unemployment } \\
\hline & $\mathrm{C}_{1}$ & $\mathrm{C}_{2}$ & $\mathrm{C}_{3}$ & $\mathrm{C}_{4}$ \\
\hline $\mathrm{C}_{1}$ & 0.609 & 0.089 & 0.210 & 0.091 \\
\hline $\mathrm{C}_{2}$ & 0.108 & 0.660 & 0.147 & 0.085 \\
\hline $\mathrm{C}_{3}$ & 0.081 & 0.179 & 0.599 & 0.141 \\
\hline $\mathrm{C}_{4}$ & 0.048 & 0.133 & 0.126 & 0.693 \\
\hline
\end{tabular}

probabilities show the likelihood of transition to more generous social security systems, an upgrade in this paper.

Table 1 shows the transition probability matrix for total public social expenditure and social protection benefits as percent of GDP. There is $66 \%$ probability that the proportional expenditure of club 1 remains the same next year, thus showing persistence that is similar to the one of club 2 . For clubs 3 and 4 the relevant nontransition probability is lower, $57.6 \%$ and $57.9 \%$ respectively, which implies that the proportional public social expenditure carries lower persistence for the less generous social security systems, i.e. the Southern club and the Anglo-Saxon. The off-diagonal matrix elements in Table 1 are quite substantial in magnitude in the case of transition from club 1 to 2 and 4 $\left(P_{12}=13.6 \%\right.$ and $\left.P_{14}=14.3 \%\right)$, from club 2 to $1\left(P_{21}=16.4 \%\right)$, from club 3 to 2 and $4\left(P_{32}=12.8 \%\right.$ and $\left.P_{34}=19.8 \%\right)$, and finally from club 4 to $3\left(P_{43}=24.3 \%\right)$. Note the pattern in off-diagonal elements that emerges as the clubs of the Southern and the Anglo-Saxon appear to exhibit high transition probabilities between them, whilst similar high transition probabilities are observed between the Nordic and Continental clubs. This pattern could be interpreted as essentially a convergence of the four clubs into two that is Nordic with Continental the one club and the Aglo-Saxon with the Southern the other club. Similar picture emerges for social protection benefits as percent of GDP. ${ }^{3}$

Table 2 reports the transition probability matrix the risk of poverty rate before and after social transfers. We observe that the persistence of the risk of poverty rate reduces after social transfers only for the generous social systems, in particular for club 1 and less so for club 2 . For clubs 3 and 4 , at best the probability of risk of poverty rate remains the same after social transfers. This result verifies the general belief that traditionally socially minded countries are more effective in delivering results in terms of lowering poverty. As it turns out, if you are within club 3 (club 4) you face a transition probability after social transfers that improves your odds of facing a risk of poverty of type club 2 (club 3 ).

Table 3 reports the transition probability matrix for the employment and the unemployment rate. The persistence in unemployment is higher, 69.3\%, for club 4, the Anglo-Saxon club, characterized by a highly unregulated labor market, in comparison to the persistence for club 1, the Nordic club. The off-diagonal elements show that there exist high transition probabilities from club 3 and club 4 to club 2, whereas clubs 1 and 2 transit to club 3 . For the employment, persistence appears to form two major groups of clubs that are 3,4, and 1, 2 .
Table 4

Half life to steady-state distributions.

\begin{tabular}{lll}
\hline & $\lambda_{2}$ & Half life \\
\hline Social expenditure (\% GDP) & 0.5922 & 1.3230 \\
Social expenditure (mil. euro) & 0.4765 & 0.9351 \\
Social protection benefits (\% GDP) & 0.6047 & 1.3780 \\
Social protection benefits (mil. EUR) & 0.4588 & 0.8896 \\
Risk of poverty after social transfers & 0.4948 & 0.9851 \\
Risk of poverty before social transfers & 0.5624 & 1.2043 \\
Employment & 0.5556 & 1.1794 \\
Unemployment & 0.5772 & 1.2613 \\
\hline
\end{tabular}

A relevant question is how fast the actual distribution approaches the steady state one. This can be assessed from the system's 'half life' obtained as:

$h l=-\frac{\ln 2}{\ln \left|\lambda_{2}\right|}$

where $\lambda_{2}$ is the second eigenvalue of the one-step probability matrix.

Table 4 shows a rather fast pace as half life ranging from 0.93 years in the case of total social expenditure in million euros to 1.37 years. Note that the half life falls if one uses million of euros rather than percent of GDP, insinuating that the pace of which the actual distribution approaches the steady state is lower if one takes into account also the evolution of GDP. Also, the pace of adjustment is higher for poverty risk after social transfers compared to before social transfers, whereas for the labor market the pace for employment is close to the one for unemployment.

\section{Conclusions}

A striking finding that emerges from the transition probability matrix for social expenditure as percent of GDP is the convergence of the four social clubs into two that is between the Nordic and the Continental club and between the Anglo-Saxon and the Southern club. High persistence is also observed regarding unemployment in club 4, the Anglo-Saxon club, characterized by a highly unregulated labor market. Lastly, the half life statistics show fast pace across all variables of our interest.

\section{References}

Bertola, G., 2007. Welfare policy integration inconsistencies. In: Berger, Helge, Moutos, Thomas (Eds.), Designing the New European Union. Elsevier, Amsterdam, pp. 91-120.

Christodoulakis, G.A., 2007. Markovian credit risk transition probabilities under inequality constraints. Journal of Credit Risk 3 (3), 25-39.

European Commission, 2006. Implementing the Renewed Lisbon Strategy for Growth and Jobs: a Year of Delivery. Communication to the Spring European Council, Brussels.

Eurostat, 2006. Population and Social Conditions: Social Protection Expenditures. Various Issues.

Esping-Andersen, G., 1990. The Three Worlds of Welfare Capitalism. Polity Press, Cambridge, UK.

Kloek, T., van Dijk, H.K., 1978. Bayesian estimates of equation system parameters: an application of integration by Monte Carlo. Econometrica 46 (1), 1-19.

van Dijk, H.K., Kloek, T., 1980. Further experience in Bayesian analysis using Monte Carlo Integration. Journal of Econometrics 14, 307-328.

\footnotetext{
${ }^{3}$ Note that our approach uncovers the entire empirical posterior distribution of transition probabilities, for which statistical inference is available under request.
} 